\title{
APAKAH GOOD UNIVERSITY GOVERNANCE BERHUBUNGAN DENGAN RELIGIUSITAS MAHASISWA?
}

\author{
Lulu Amalia Nusron ${ }^{1,}$ Sri Widodo ${ }^{2,}$ Dekeng Setyo Budiarto ${ }^{3}$ \\ 1,2,3 Universitas PGRI Yogyakarta \\ Jl. IKIP PGRI I Sonosewu No.117, Sonosewu, Ngestiharjo, Kasihan, Bantul \\ E-mail: lulu.amalia@upy.ac.id
}

diterima: 1/3/2019; direvisi: 31/3/2019; diterbitkan: 24/9/2019

\begin{abstract}
The University that is trusted by the community should have a moral responsibility on students ethics and behavior who are graduated. As part of its responsibility to the community, universities must have good governance and produce quality graduates. This study aims to examine the relationship of good university governance that is proxied by the value of accreditation with the level of student religiosity both intrinsic and extrinsic religiosity. This study uses 123 samples from active students majoring in Accounting who have accreditation A and B. This research is a quantitative study with purposive sampling as a sampling technique. The results of the study show that there are differences in the level of religiosity based on good university governance. The better management of higher education, the higher the religiosity of students. This research implies that universities should not only produce graduates who have high intelligence but also graduates who have good religiosity.
\end{abstract}

Keywords: good university governance, intrinsic religiosity, extrinsic religiosity, accreditation.

\section{PENDAHULUAN}

Pendidikan tinggi keagamaan Islam merupakan pilihan bagi orang tua dan mahasiswa yang tertarik pada ilmu umum tanpa meninggalkan nilai-nilai syariat di dalamnya. Pendidikan tinggi Islam harus lebih bisa mengaplikasikan nilai-nilai syariat di dalam aturan dan teknis kerja maupun pengajaran kepada mahasiswa. Nilai-nilai Islam harus benar-benar diterapkan dalam setiap aktivitas pimpinan, karyawan, bahkan sampai pada mahasiswanya. Dengan memilih pendidikan tinggi berbasis agama Islam diharapkan dapat menambah ilmu keagamaan baik secara aqidah maupun akhlaknya. Oleh karena itu, pendidikan tinggi keagamaan Islam harus selalu di dalam batasan normanorma Islam untuk menggapai progres yang bersifat positif (Putri et al, 2015; Silahuddin, 2016; Suherman, 2018).

Selain mengunggulkan nilai-nilai keagamaan, pendidikan tinggi harus mampu bersaing satu sama lain untuk menjaga kualitas. Mutu lulusan adalah konsistensi antara kapabilitas mahasiswa dengan visi misi pendidikan tinggi sehingga tujuan dan harapan mereka tercapai. Oleh karena itu, penting bagi perguruan tinggi untuk memiliki pertimbangan dalam mencapai keinginan dan kebutuhan stakeholder yaitu dengan mempersiapkan mahasiswa yang bermutu (Nikmatuttisaroh, 2014).

Salah satu cara menjaga kualitas adalah dengan menerapkan tata kelola yang baik. Tata kelola sebuah perguruan tinggi tergantung pada faktor-faktor seperti visi dan misi; aturan; pedoman tata kelola; student body; sumber daya manusia; infrastruktur; tridharma perguruan tinggi; kerjasama internasional; visiting lecture; yang terintegrasi satu sama lain. Tata kelola perguruan tinggi akan menjadi maksimal jika keseluruhan faktor di atas saling terintegrasi (Nulhaqim et al, 2015).

Tata kelola perguruan tinggi atau good university governance (GUG) dapat 
merujuk pada prinsip good corporate governance (GCG) yang didasari dari teori stakeholder. Prinsip-prinsip good corporate governance juga dapat diberlakukan pada instansi berbentuk universitas. Hatmodjosoewito (2010) menyatakan bahwa model baru yang menerapkan asas-asas tata kelola akan menjadi lebih berhasil apabila model baru tersebut didukung dengan dorongan yang dapat memberikan sesuatu yang yang lebih kontributif, yaitu dorongan tata kelola universitas yang baik (good university governance spirit), dorongan otonomi kampus (autonomy spirit) dan dorongan pemberdayaan masyarakat kampus (community empowering spirit). Prinsip-prinsip tersebut akan mempengaruhi kinerja layanan, produk pendidikan, dan kualitas mahasiswa.

Terlebih jika tata kelola universitas dilandasi nilai-nilai Islam, maka akan semakin banyak aktivitas kampus yang mengacu pada hal keagamaan dan dapat meningkatkan kinerja pemimpin, karyawan, maupun mahasiswanya. Hal ini didukung oleh penelitian dari Adhi dan Olivia (2017) yang mengungkapkan bahwa pelaksanaan dan peraturan manajemen sumber daya manusia yang dilakukan oleh perusahaan yang berbasis nilai nilai Islam berpengaruh terhadap perilaku kerja karyawan. Hal ini berdampak pada kinerja perusahaan yang semakin meningkat. Selain itu, hasil penelitian Alfisyah dan Anwar (2018) juga menunjukkan adanya pengaruh signifikan antara perilaku keagamaan terhadap hasil kerja karyawan muslim Kantor Pusat PT. Perkebunan Nusantara XI. Kedua peneliti melihat adanya beberapa kegiatan kerohanian yang sering dilakukan pada waktu kosong kerja karyawan di Kantor Pusat PT. Perkebunan Nusantara XI. Adapun kegiatan tersebut antara lain adalah kajian rutin, doa pagi bersama sebelum waktu kerja di mulai, kegiatan istighosah yang juga rutin dilakukan, dan sebagainya. Dengan adanya kegiatankegiatan tersebut tentunya dapat mendorong faktor agama dalam suasana psikologis karyawan, dimana hal tersebut dapat meningkatkan kinerja karyawan yang lebih baik lagi.

Telah banyak dilakukan penelitian yang berkaitan dengan kinerja perguruan tinggi, diantaranya penelitian Amilin (2016) yang menyatakan prinsip-prinsip GUG berpengaruh positif terhadap kinerja manajerial. Wahyudin, Ahmad dan Kiswanto (2017) juga menampilkan variabel GUG terbukti memiliki pengaruh secara signifikan terhadap susunan organisasi, pengelolaan perencanaan, dan kinerja pengelolaan keuangan. Terdapat pengaruh yang positif dan signifikan antara GUG dengan kinerja dosen dan tidak memiliki pengaruh pada kinerja perguruan tinggi swasta secara keseluruhan yang ditunjukkan dalam penelitian dari Hamzah, Siswoyo, dan Zainal (2018). Penelitian Widjajanti dan Eviatiwi (2015) menunjukkan bahwa variabel GUG memberikan dampak positif dan signifikan terhadap pelayanan yang memuaskan dan pelayanan yang memuaskan dapat mempengaruhi kepercayaan mahasiswa secara positif. Sedangkan GUG tidak memiliki pengaruh pada kepercayaan mahasiswa. Artinya, mahasiswa tidak dapat langsung percaya jika tidak diberikan bukti konkret yang dapat mahasiswa rasakan.

Peningkatan kinerja dan penerapan tata kelola perguruan tinggi yang berkualitas dapat dibuktikan dengan pencapaian nilai akreditasi yang baik. BAN-PT (Badan Akreditasi Nasional Perguruan Tinggi) telah menetapkan standar yang harus dipenuhi oleh perguruan tinggi atau program studi untuk mendapatkan nilai akreditasi bahwa perguruan tinggi atau program studi tersebut telah melaksanakan program 
pendidikan dan menghasilkan mutu lulusan yang sesuai dengan standarnya. Dengan mendapatkan nilai akreditasi, perguruan tinggi akan lebih diakui dan mendapatkan nilai tambah di mata masyarakat (Prasetyo, 2014).

Saat ini telah ada beberapa pendidikan tinggi keagamaan Islam di Yogyakarta yang telah terakreditasi dengan baik, seperti Universitas Islam Indonesia, Universitas Ahmad Dahlan, Universitas Muhammadiyah Yogyakarta, Universitas 'Aisyiyah, Universitas Nahdatul Ulama dan STEI Yogyakarta, yang telah mendapatkan akreditasi institusi baik predikat A maupun B. Berdasarkan data peringkat kelas dunia Webometrics edisi Juli 2018, UII menduduki peringkat 3636, UMY menduduki peringkat 3966, UAD menduduki peringkat 5083 , dan UNISA menduduki peringkat 5835. Sedangkan berdasarkan Kementrian Ristekdikti 2018, UII menduduki peringkat 29, UMY menduduki peringkat 42, dan UAD menduduki peringkat 58. Perguruan tinggi dengan basis agama Islam ini relatif memiliki tujuan yang sama yaitu membentuk lulusan sarjana dengan akhlakul karimah, wawasan yang luas, dan terintegrasi dengan nilai-nilai Islam. Namun, dengan mendapatkan predikat atau akreditasi A dan B tentu terdapat penerapan tata kelola yang berbeda dan mungkin akan berpengaruh pada kualitas lulusan mahasiswanya.

Penelitian-penelitian

yang berkaitan dengan tingkat religiusitas juga banyak dilakukan. Peterson et al (2010) mengemukakan bahwa terdapat pengaruh yang positif dan signifikan antara religiusitas dengan etika. Penelitian ini didukung oleh Pemayun dan I Gusti (2018) yang menunjukkan tingkat religiusitas akan naik jika persepsi etika naik dan sebaliknya. Silahuddin (2016) menyatakan bahwa tingkat religiusitas mahasiswa di perguruan tinggi keagamaan Islam negeri lebih tinggi dibandingkan perguruan tinggi umum negeri. Selain itu beberapa peneliti juga menghubungkan antara religiusitas dengan gender dan perilaku etis. Walker et al, (2012) menyatakan bahwa religiusitas tidak berhubungan dengan perilaku etis. Peneliti lain menemukan bahwa religiusitas antara laki-laki dan wanita tidak berbeda terutama ketika sudah menjadi pekerja profesional dan mengikuti kultur pada perusahaan (Westbrook et al., 2011; Budiarto et al, 2017).

Meskipun para peneliti telah banyak melakukan penelitian yang berkaitan dengan tingkat religiusitas, namun masih sangat jarang peneliti yang menunjukkan hubungan tata kelola perguruan tinggi dengan religiusitas. Hal ini menjadi bagian dari motivasi dan fokus peneliti untuk melakukan penelitian apakah terdapat perbedaan antara tata kelola perguruan tinggi yang diukur dari nilai akreditasi dengan tingkat religiusitas mahasiswa.

\section{TINJAUAN PUSTAKA}

Good University Governance

Good University Governance

(GUG) merupakan suatu konsep tata kelola perguruan tinggi yang diadopsi dari konsep tata kelola perusahaan atau Good Corporate Governance (GCG). Organisation for Economic Cooperation and Development (OECD) (1998) menyatakan kegiatan bisnis perusahaan dapat berjalan dengan baik jika menggunakan sistem GCG karena dapat memberikan arahan, melakukan kendali, membagi tugas, hak, dan kewajiban untuk para pemangku kepentingan yang memiliki pengaruh pada perusahaan.

Menurut Rosyid, Agus, dan Miftahul (2014), standar perilaku, struktur organisasi, pengendalian, dan pelaporan kepada pihak luar merupakan prinsip- 
prinsip GCG yang diadopsi oleh perguruan tinggi dalam menerapkan GUG. Selain itu, konsep GUG juga didasarkan pada teori pemangku kepentingan (stakeholder theory) yang memiliki pengaruh terhadap proses jalannya suatu perusahaan, seperti para pemegang saham, karyawan, kreditur, pelanggan, pemerintah, dan masyarakat lainnya. Tujuan perusahaan yang baik adalah tidak beroperasi demi kepentingan keuntungan semata, namun juga harus mampu memberikan manfaat untuk para stakeholder. Oleh karena itu, semua kepentingan harus diperhitungkan, diperhatikan, dan dipertimbangkan karena memegang peranan dan nilai-nilai yang penting bagi perusahaan (Wahyudin, Ahmad, dan Kiswanto, 2017).

Sama halnya dengan perusahaan, perguruan tinggi juga perlu memikirkan kepentingan stakeholder. Salah satunya adalah mahasiswa dimana proses belajar dan output yang dihasilkan dapat mempengaruhi nilai perguruan tinggi dan perlu dikelola secara khusus. Studi tentang GUG diharapkan dapat memberikan kontribusi penting bagi para pengelola sebagai salah satu referensi dalam mengelola perguruan tinggi.

Nilai-Nilai Islami

Nilai-nilai Islami merupakan sesuatu yang berharga yang dapat menjadi pedoman manusia dalam menjalani kehidupannya. Nilai-nilai Islami juga merupakan sifat-sifat dari ajaran Islam yang memiliki manfaat untuk manusia sebagai bekal hidup di dunia dan akhirat yang mengatur hubungan manusia dengan tuhan dan alam (Suherman, 2018).

Dalam perkembangannya, penerapan tata kelola perusahaan sudah mulai berproses menghayati nilai-nilai Islam. Hal in dibuktikan dengan banyaknya entitas atau perusahaan yang memiliki label syariah hadir di tengahtengah masyarakat. Berkah (2014) menyatakan bahwa terdapat perbedaan ajaran yang diterapkan di dalam tata kelola perusahaan dengan nilai islam yaitu berbasis pada tauhid, prinsip syariah, dan memiliki stakeholder yang lebih luas.

Nilai-nilai Islam yang diterapkan dalam tata kelola perguruan tinggi atau good university governance (GUG) juga akan lebih berdampak positif pada kinerja civitas akademika. Hal ini didukung oleh penelitian dari Parboteeah et al. (2009); Amaliah et al. (2013) yang menyatakan bahwa kinerja seorang individu dapat dipengaruhi oleh kepercayaan dan pemahaman yang kuat terhadap agama. Selain GUG, penerapan nilai-nilai Islam pada pendidikan agama memiliki peranan yang sangat penting untuk membangun kualitas mahasiswa. Alam (2016) menyatakan konsep pendidikan Islam tidak bisa dipisahkan dari konsepsi ketuhanan. Pendidikan agama Islam di perguruan tinggi memiliki tujuan agar peserta didik dapat mendalami nilai-nilai ajaran Islam dan diterapkan dalam kehidupan mereka sehari-hari.

\section{Religiusitas (Intrinsik dan Ekstrinsik)}

Pada umumnya, semua agama memiliki tujuan yang sama yaitu menjalani perintah dan menjauhi larangan Tuhan. Agama merupakan pedoman untuk mengontrol perilaku moral seseorang. Keterikatan seseorang terhadap agama dapat mengukur kualitas iman, keyakinan, dan praktik penerapan nilai-nilai agama yang telah dipelajari dalam kehidupan sehari-hari. Religiusitas mengacu pada iman yang dimiliki seseorang dan sejauh mana mereka mengejar jalan yang telah ditetapkan oleh Tuhan. Seseorang yang religius akan dapat mengawasi perilakunya sehingga dapat menjauhkan 
diri dari perilaku yang tidak bermoral (Basri, 2015).

Singhapakdi et al (2013) menyajikan dua sudut pandang dari sikap religiusitas yaitu religiusitas intrinsik dan religiusitas ekstrinsik. Religiusitas intrinsik lebih menunjuk pada motivasi yang didasarkan pada tujuan yang melekat pada tradisi agama itu sendiri. Religiusitas instrinsik merupakan indikasi bahwa seseorang memiliki komitmen untuk memeluk agama karena tujuan spiritual yang lebih tinggi. Hal ini menggambarkan dorongan dan keterikatan dalam diri seseorang pada agama dan prinsipprinsipnya merupakan bagian dari agamanya. Artinya, individu yang memiliki religiusitas intrinsik cenderung menggunakan agama sebagai tujuan hidup dan mengimplementasikan nilainilai agama didalam kehidupan (Stavrova dan Siegers, 2014; Chowdhury, 2018).

Religiusitas ekstrinsik mengacu pada motivasi utilitarian yang mungkin mendasari perilaku keagamaan seseorang. Religiusitas ekstrinsik berarti seseorang akan memiliki keterlibatan religius untuk alasan-alasan yang mementingkan diri sendiri dengan menggunakan agama sebagai kekuasaan, pelindung, pelarian status sosial, partisipasi dalam kelompok keagamaan, dan pertahanan ego. Artinya, individu tidak melihat agama sebagai tujuan akhir sehingga iman mereka akan mudah berubah jika ada yang bisa memberikan rasa nyaman yang lebih besar. Tujuan individu memegang agama secara ekstrinsik adalah agar mendapatkan rasa aman dan memiliki ikatan sosial.

Hubungan tata kelola universitas dengan religiusitas intrinsik

$$
\text { Menurut Allport }
$$

religiusitas intrinsik adalah pertanda seseorang yang memiliki keterikatan pada agama dan digunakan untuk kebutuhan batin atau jiwanya. Orang menganggap agamanya sebagai tujuan hidup. Intrinsik berfungsi sebagai lindungan diri yang kuat untuk memastikan bahwa agama adalah bagian dari kehidupan seseorang. Mereka cenderung berkomitmen dan menjadikan agama sebagai pengatur hidup. Religiusitas intrinsik akan mendorong seseorang menggunakan iman untuk melakukan kegiatan keagamaan.

Mahasiswa yang memiliki religiusitas intrinsik akan menjadikan agama sebagai tujuan hidup mereka dan mendalami nilai-nilai keagamaan untuk diterapkan dalam kehidupan sehari-hari. Hal ini didukung oleh penelitian dari Hafizah dan Yessi (2016) yang menyatakan prinsip religiusitas intrinsik dapat mengatur tingkah laku seseorang sehingga akan menghindarkan ia untuk melakukan perbuatan curang. Nilai-nilai keyakinan agama ini dapat tumbuh jika penerapan tata kelola universitas atau GUG yang berlandaskan nilai-nilai Islam telah melekat dalam diri mahasiswa. Semakin baik GUG yang diterapkan, maka semakin tinggi juga tingkat reliugiusitas mahasiswa.

Hubungan tata kelola universitas dengan religiusitas ekstrinsik

Seseorang yang memerlukan agama untuk menggapai tujuan pribadi disebut orang yang memilki religiusitas ekstrinsik. Karakter ekstrinsik berperan sebagai alat untuk memenuhi kepentingan pribadi dan kepuasan dirinya. Faktor duniawi yang sangat menguntungkan dapat memotivasi seseorang untuk mencari cara agar mendukung kepentingannya (Allport, 1950). Sedangkan Walker et al (2012) berargumen bahwa kita seharusnya tidak mengharapkan bahwa agama akan mempengaruhi etika seseorang yang memiliki religiusitas ekstrinsik. Hal ini 
karena mereka yang memiliki orientasi ekstrinsik tidak mungkin memiliki peran dan harapan untuk melarang perilaku tidak etis sesuai dengan agamanya.

Hasil penelitian Wibisono dan Taufik (2017) telah membuktikan adanya keterkaitan antara penyesuaian agama ekstrinsik dengan aliran agama pada mahasiswa muslim yang menganggap diri mereka lebih murni. Penyesuaian keberagamaan yang ekstrinsik dimana individu cenderung membangun tendensi untuk dirinya dari keberagamaan yang dijalani. Dampak yang kadang berlebihan dari hal ini adalah kecenderungan individu untuk memandang bahwa kelompok keagamaan yang diikutinya merupakan bentuk tafsir paling akurat dari nilai keagamaan yang diyakininya. Mahasiswa yang memiliki penyesuaian religiusitas ekstrinsik akan membentuk agama sebagai pelindung guna memperoleh berbagai kondisi emosional yang diharapkan, penghibur di kala memperoleh kesusahan, mempertahankan ego, dan meneguhkan status sosial. Dengan penerapan GUG secara islami dengan benar, maka hakikatnya nilai-nilai Islam melekat dalam diri mahasiswa dan akan mempengaruhi tingkat religiusitas ekstrinsik antar mahasiswa.

\section{METODE PENELITIAN}

Penelitian ini menggunakan sumber data primer yang didapat dari hasil sebaran kuesioner kepada mahasiswa. Pendistribusian kuesioner dilakukan secara survei online dan secara langsung kepada responden. Populasi dalam penelitian ini adalah mahasiswa S-1 yang sedang menempuh pendidikan di perguruan tinggi yang ada di Yogyakarta dengan nilai akreditasi A dan B, yaitu: (1) Universitas Islam Indonesia, (2) Universitas Ahmad
Dahlan, (3) Universitas Muhammadiyah Yogyakarta, (4) Universitas 'Aisyiyah, (5) Universitas Nahdatul Ulama, dan (6) STEI Yogyakarta.

Teknik pengambilan sampel menggunakan metode purposive sampling. Purposive sampling merupakan teknik penentuan sampel dengan pertimbangan atau kriteria tertentu (Sugiyono, 2011). Adapun pertimbangan atau kriteria yang digunakan oleh peneliti dalam menetapkan jumlah sampel penelitian, yaitu: 1) Mahasiswa aktif jurusan Akuntansi; 2) Mahasiswa yang sedang menempuh pendidikan di perguruan tinggi Islam dengan akreditasi A atau B.

Variabel religiusitas diukur dengan 20 pertanyaan yang dibagi menjadi 2 bagian yaitu religiusitas intrinsik dengan 12 pertanyaan dengan indikator pribadi seperti tidak mementingkan diri sendiri, relevansi dengan kehidupan, penghargaan keyakinan, menjaga kepercayaan, asosiasi, dan yang paling utama. Religiusitas ekstrinsik dengan 8 pertanyaan dengan indikator kelembagaan seperti keegoisan, kompartemen, komunal instrumental, perhatian terhadap perkembangan perifer dan kausal iman (Basri, 2015). Pertanyaan tersebut diukur menggunakan skala Likert 7 poin dimulai dari skala 1 yaitu tidak setuju sampai dengan skala 7 yaitu sangat setuju. Sedangkan variabel good university governance (GUG) menggunakan proksi akreditasi yang diukur dengan skala nominal, dimana nilai 1 untuk akreditasi A dan 2 untuk akreditasi B. Nilai akreditasi merupakan pengakuan dan pencapaian perguruan tinggi terhadap program pendidikan dan mutu lulusan (Prasetyo, 2014).

Penelitian ini menggunakan software SPSS. Untuk analisis data menggunakan uji validitas, reliabilitas, dan normalitas. Untuk pengujian hipotesis menggunakan uji beda. 


\section{HASIL DAN PEMBAHASAN}

Berdasarkan hasil penyebaran kuesioner diperoleh responden sejumlah 123 yang kemudian dianalisis berdasarkan karakteristik responden yang dijelaskan pada Tabel 1.

Tabel 1: Karakteristik Responden

\begin{tabular}{lccc} 
& $\begin{array}{c}\text { Akreditasi } \\
\text { A }\end{array}$ & $\begin{array}{c}\text { Akreditasi } \\
\text { B }\end{array}$ & Persentase \\
\hline Akreditasi & & & \\
Universitas & 81 & & $65,9 \%$ \\
Akreditasi A & & 42 & $34,1 \%$ \\
Akreditasi B & & & \\
\hline Jenis kelamin: & & & \\
Wanita & 51 & 32 & $67,5 \%$ \\
Laki-laki & 30 & 10 & $32,5 \%$ \\
\hline Semester: & & & \\
Semester 2 & 22 & 18 & $32,5 \%$ \\
Semester 4 & 28 & 14 & $34,1 \%$ \\
Semester 6 & 31 & 10 & $33,3 \%$ \\
\hline Sumber: Data diah
\end{tabular}

Sumber: Data diolah, 2018

Tabel 1 menunjukkan bahwa jumlah responden yang berpartisipasi berasal dari perguruan tinggi akreditasi A sebanyak 81 orang $(65,9 \%)$ yang didalamnya berjenis kelamin wanita sebanyak 51 orang dan laki-laki 30 orang. Dari 81 orang tersebut sedang menempuh pendidikan di semester 2 sebanyak 22 orang, semester 4 sebanyak 28 orang, dan semester 6 sebanyak 31 orang. Adapun jumlah responden yang berasal dari perguruan tinggi akreditasi $\mathrm{B}$ adalah sebanyak 42 orang $(34,1 \%)$ dengan jenis kelamin wanita sebanyak 32 orang dan laki-laki sebanyak 10 orang. Dari 42 orang tersebut sedang menempuh pendidikan di semester 2 sebanyak 18 orang, semester 4 sebanyak 14 orang, dan semester 6 sebanyak 10 orang.

Setelah karakteristik responden dianalisis, tahap selanjutnya adalah analisis data yaitu uji validitas, reliabilitas, dan normalitas. Hasil pengujian validitas menggunakan pearson correlation menunjukkan bahwa masing-masing item pertanyaan dalam variabel religiusitas intrinsik dan ekstrinsik adalah valid
(Tabel 2 dan Tabel 3). Hasil uji reliabilitas pada tabel 4 menunjukkan bahwa seluruh variabel memiliki reliabilitas > 0,7 yang berarti jawaban terhadap pernyataan kuesioner adalah konsisten atau stabil. Tabel 5 menunjukkan bahwa pengujian normalitas data menggunakan Kolmogorov Smirnov test menghasilkan nilai probalilitas $>0,05$ artinya seluruh data terdistribusi dengan normal.

Pengujian hipotesis pada penelitian ini menggunakan independent sample t-test. Tabel 6 menunjukkan hasil uji beda pada variabel religiusitas intrinsik dimana ratarata nilai untuk tingkat religiusitas intrinsik pada mahasiswa yang sedang menempuh pendidikan di perguruan tinggi keagamaan akreditasi A lebih tinggi dibandingkan dengan mahasiswa yang sedang menempuh pendidikan di perguruan tinggi keagamaan akreditasi B. Selanjutnya, terdapat 7 item instrumen yang tingkat probabilitasnya kurang dari 0,05 (signifikan) yaitu poin 3 , $4,5,6,8,11$, dan 12. Hasil ini menunjukkan bahwa religiusitas intrinsik mahasiswa perguruan tinggi akreditasi A lebih baik daripada mahasiswa perguruan tinggi akreditasi B.

Tabel 6 menunjukkan hasil uji beda pada variabel religiusitas ekstrinsik dimana ratarata nilai untuk tingkat religiusitas ekstrinsik pada mahasiswa yang sedang menempuh pendidikan di perguruan tinggi keagamaan akreditasi A juga lebih tinggi. Selanjutnya, terdapat 4 item instrumen yang tingkat probabilitasnya kurang dari 0,05 (signifikan) yaitu poin $3,5,6$, dan 8 . Hasil pengujian ini bahwa religiusitas ekstrinsik mahasiswa perguruan tinggi akreditasi A lebih baik daripada mahasiswa perguruan tinggi akreditasi $\mathrm{B}$. 
Tabel 2: Hasil Uji Validitas Religiusitas Intrinsik

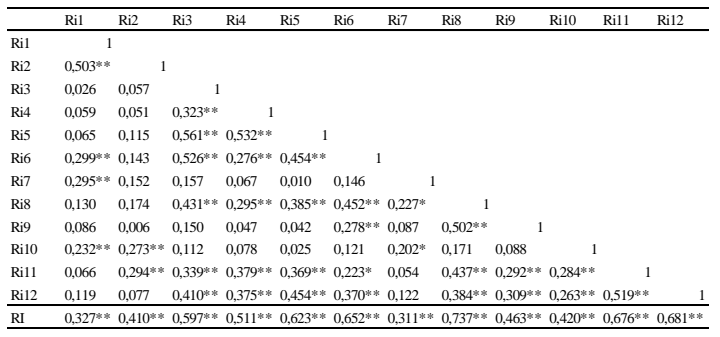

Sumber: Data diolah, 2018

Tabel 3: Hasil Uji Validitas Religiusitas Ekstrinsik

\begin{tabular}{|c|c|c|c|c|c|c|c|c|}
\hline & Re1 & Re2 & Re3 & Re4 & Re5 & Re6 & Re7 & $\mathrm{Re} 8$ \\
\hline Re1 & 1 & & & & & & & \\
\hline $\mathrm{Re} 2$ & $0,401^{* * *}$ & 1 & & & & & & \\
\hline Re3 & 0,120 & $0,300^{* *}$ & 1 & & & & & \\
\hline Re4 & $0,417 * *$ & $0,517^{* * *}$ & $0,356^{* *}$ & 1 & & & & \\
\hline es & 0,141 & $0,308^{* *}$ & $0,559^{* *}$ & $0,319 * *$ & 1 & & & \\
\hline Re6 & 0,012 & 0,022 & $0,365^{* *}$ & 0,150 & 0,177 & 1 & & \\
\hline $\operatorname{Re} 7$ & $0,396^{* * *}$ & $0,464^{* *}$ & $0,279^{* *}$ & $0,615^{* *}$ & $0,380^{* *}$ & $0,257 * *$ & 1 & \\
\hline Re8 & $0,216^{*}$ & $0,338^{* *}$ & $0,572^{* *}$ & $0,343^{* * *}$ & $0,531 * *$ & 0,144 & $0,328^{* *}$ & 1 \\
\hline $\mathrm{RE}$ & $0,489 * *$ & $0,624^{* * *}$ & $0,727^{* *}$ & $0.687^{* * *}$ & $0,679 * *$ & $0,406^{* * *}$ & $0,691 * *$ & $0,721^{* *}$ \\
\hline
\end{tabular}

Sumber: Data primer diolah tahun 2018;

Keterangan: * $\mathrm{Sig}<5 \%$; ** $\operatorname{sig}<1 \%$

Tabel 4: Hasil Uji Reliabilitas

\begin{tabular}{lccc}
\hline Variabel & Cronbach Alpha & Batas & Keterangan \\
\hline Religiusitas Intrinsik & 0,788 & 0,700 & Reliabel \\
Religiusitas ekstrinsik & 0,773 & 0,700 & Reliabel \\
\hline
\end{tabular}

Sumber: Data primer diolah tahun 2018

Tabel 5: Hasil Uji Normalitas Data

\begin{tabular}{lcc}
\hline Variabel & P value & Keterangan \\
\hline Religiusitas Intrinsik & 0,246 & Normal \\
Religiusitas ekstrinsik & 0,322 & Normal \\
\hline
\end{tabular}

Sumber: Data primer diolah tahun 2018

Tabel 6: Hasil Pengujian Religiusitas Intrinsik

\begin{tabular}{|c|c|c|c|c|c|}
\hline \multirow[b]{2}{*}{ No } & \multirow[b]{2}{*}{ Instrumen } & \multicolumn{2}{|c|}{ Mean } & \multirow{2}{*}{$\begin{array}{l}\text { Levenc's } \\
\text { test }\end{array}$} & \multirow[b]{2}{*}{$P$ value } \\
\hline & & Akreditasi A & $\begin{array}{l}\text { Akrdeditasi } \\
\text { B }\end{array}$ & & \\
\hline 1. & Kewajiban memperdalam ilmpagama & 4,48 & 3,90 & 0,541 & 0,062 \\
\hline & Tetap beribadah di masjid apapun kead. & 4,10 & 3,48 & 0,329 & \\
\hline 3. & Membawa nilai-nilai agama dalam kchidupan & 6,28 & 4,71 & 0,108 & $0,000^{* *}$ \\
\hline 4. & Berdoa secara khusuk & 5,84 & 4,71 & & $0,000^{* *}$ \\
\hline 5. & Persasan kedekatan dengan Allah & 6,58 & 4,57 & $0,000 * *$ & $0,000^{* *}$ \\
\hline 6. & $\begin{array}{l}\text { Mementingkan kelompok agama daripada } \\
\text { kelompok lain }\end{array}$ & 6,09 & 4,55 & 0,488 & $0,000^{* *}$ \\
\hline 7. & Menjalankan ajann agama dalam kchidupan & 4,00 & 3,74 & 0,089 & 0,378 \\
\hline & Agama merupalan solusis semua permasal hat & & 4,19 & 080 & $0,000^{* *}>0$ \\
\hline 9. & $\begin{array}{l}\text { Tidak ada hal lain yang lebih penting selain } \\
\text { agama }\end{array}$ & 5,06 & 4,60 & $0,013^{*}$ & 0,137 \\
\hline 10. & $\begin{array}{l}\text { Nilai-nilai moral dalam kehidqpan jug penting } \\
\text { sclain agama }\end{array}$ & 4,48 & 3,90 & $0,011^{*}$ & 0,069 \\
\hline 11. & Memohonperlindungan Allah dengan berdoa & 5,46 & 4,50 & 0,513 & $0,001^{*} *$ \\
\hline
\end{tabular}

Sumber: Data primer diolah tahun 2018;

Keterangan: * Sig $<5 \%$;** sig $<1 \%$
Tabel 8: Hasil Pengujian Religiusitas Ekstrinsik

\begin{tabular}{|c|c|c|c|c|c|}
\hline \multirow[b]{2}{*}{ No } & \multirow[b]{2}{*}{ Instrumen } & \multicolumn{2}{|c|}{ Mean } & \multirow{2}{*}{$\begin{array}{c}\text { Levene's } \\
\text { test }\end{array}$} & \multirow[t]{2}{*}{$P$ value } \\
\hline & & Akreditasi A & $\frac{\text { Akreditasi }}{\text { B }}$ & & \\
\hline 1 & $\begin{array}{l}\text { Agama memberi rasa nyaman ketika } \\
\text { menghadapi cobaan }\end{array}$ & 4,99 & 4,93 & 0,319 & 0,778 \\
\hline 2 & $\begin{array}{l}\text { Tempat pendidikan mengajarkan saya untuk } \\
\text { berdoa secara khusulk }\end{array}$ & 5,15 & 4,79 & 0,783 & 0,061 \\
\hline 3 & $\begin{array}{l}\text { Tidak akan mencampurkan urusanan agama } \\
\text { dengan dengan urusan lainnya }\end{array}$ & 5,99 & 4,48 & 0,074 & $0,000^{* *}$ \\
\hline 4 & $\begin{array}{l}\text { Beribadah di masjid adalah kewaiiban yang } \\
\text { menyenangkan }\end{array}$ & 5,46 & 5,10 & 0,857 & 0,097 \\
\hline 5 & $\begin{array}{l}\text { Masjid meruppkan salah satu tempat yang baik } \\
\text { untuk beraktivitas sosial }\end{array}$ & 5,88 & 4,83 & $0,003^{*}$ & $0,000^{* *}$ \\
\hline 6 & $\begin{array}{l}\text { Agama berhubungan dengan kemakmuran } \\
\text { seseorang }\end{array}$ & 5,16 & 3,95 & 0,875 & ** \\
\hline 7 & $\begin{array}{l}\text { Menjadi bagian dari kelompok agama dapat } \\
\text { membuat seseorang menjadi lebih baik }\end{array}$ & 5,12 & 4,86 & $0,041^{*}$ & 0,088 \\
\hline 8 & $\begin{array}{l}\text { Agama berhubungan dengan kebahagiaan dan } \\
\text { kedamaian }\end{array}$ & 6,12 & 5,02 & 0,090 & $0,000^{* * *}$ \\
\hline
\end{tabular}

Sumber: Data primer diolah tahun 2018; Keterangan: $* * \operatorname{sig}<1 \%$

Nilai akreditasi suatu perguruan tinggi merupakan sebuah pencapaian sebagai hasil pelaksanaan tata kelola universitas atau good university governance dengan baik. Artinya, penerapan GUG yang bersifat islami pada perguruan tinggi keagamaan akreditasi A lebih baik dari pada perguruan tinggi keagamaan akreditasi B. Hal ini berpengaruh terhadap kualitas mahasiswa terutama pada tingkat religiusitasnya.

Meskipun keduanya sama-sama memasukkan materi pendidikan agama dalam kurikulum mereka, namun pembentukan karakter religius pada mahasiswa bisa berbeda. Hal ini mungkin disebabkan tidak adanya perkembangan kurikulum yang dapat mengarahkan perilaku kesalehan dalam kehidupan mahasiswa. Hasil riset ini mendukung temuan Tang et al., (2008) yang menjelaskan bahwa perbedaan penerapan kurikulum dapat mengakibatkan perbedaan perilaku mahasiswa.

Syukri dan Sudiyatno (2009) menyatakan bahwa acuan pembinaan dan penerapan ilmu agama yang tepat adalah dengan menerapkan skema pembelajaran melalui silang pendapat yang mengulas tema masa kini. Mahasiswa yang mengikuti perkuliahan mata kuliah Pendidikan Agama Islam akan menghasilkan perilaku agamis dan secara otomatis juga akan menyatu pada sikap mahasiswa di unit keagamaan. Penelitian dari Fauzan (2013) juga 
menyatakan bahwa kehidupan agamis akan tercapai jika pendidikan agama ikut andil dan mampu memenuhi tujuan agama. Mahasiswa perlu memahami konsep dasar agama dan tidak hanya terbatas pada kegiatan ritual saja.

\section{KESIMPULAN DAN SARAN}

Kesimpulan dari hasil penelitian ini adalah terdapat perbedaan tingkat religiusitas baik secara intrinsik maupun ekstrinsik pada mahasiswa yang sedang menjalani pendidikan di perguruan tinggi keagamaan dengan akreditasi A dan B.

Keterbatasan penelitian ini adalah bahwa penelitian ini hanya terbatas pada satu variabel independen saja yaitu tingkat religiusitas mahasiswa. Selain itu, sampel penelitian hanya tertuju pada mahasiswa aktif jurusan Akuntansi. Oleh karena itu pada penelitian yang akan datang diperlukan kajian lebih lanjut terkait dengan good university governance dan menggunakan ukuran variabel lainnya yang memiliki relevansi dengan implementasi good governance di perguruan tinggi seperti prestasi mahasiswa baik bidang akademik maupun non akademik. Kriteria sampel penelitian bisa diperluas dengan menggunakan mahasiswa aktif semua jurusan dan mahasiswa yang telah menempuh mata kuliah etika, karena etika juga dapat dibentuk melalui tutorial (Singhapakdi et al, 2013). Penelitian ini tidak memasukkan kedewasaaan sebagai dasar pengujian, sehingga penelitian mendatang dapat menguji kedewasaan karena kedewasaan dapat mempengaruhi sikap seseorang (Walker et al, 2012)

Hasil penelitian ini menjadi kontribusi penting bagi penelitian yang akan datang yang mengangkat tema good university governance $\mathrm{di}$ Indonesia, sehingga masih sangat menarik untuk terus dilakukan di masa mendatang. Secara rasional perguruan tinggi dapat meningkatkan penerapan good university governance berlandaskan nilai-nilai Islam sesuai dengan hasil penelitian ini. Selain itu, selalu menerapkan kegiatan-kegiatan akademik dan non akademik yang berlandaskan nilai-nilai Islam dan merubah sistem pembelajaran agama agar lebih berdampak pada peningkatan iman mahasiswa. Hasil penelitian ini diharapkan memberikan masukan perguruan tinggi keagamaan agar tidak hanya menghasilkan lulusan yang hanya pandai secara intelektual saja, tetapi juga lulusan yang berkarakter dengan sifat religiusitas yang tinggi.

\section{DAFTAR PUSTAKA}

Adhi, S. M., Ofachrunnisa, O, 2017, Peran Perilaku Kerja Berbasis Praktek Manajemen Sumber Daya Manusia Islami Menuju Peningkatan Kinerja Organisasi, Jurnal Manajemen Bisnis Indonesia Vol 5 No 1, 34-47.

Alfisyah, K. D., Moch. Khoirul Anwar, 2018, Pengaruh Religiusitas Terhadap Kinerja Karyawan Muslim Kantor Pusat PT. Perkebunan Nusantara XI, Jurnal Ekonomi Islam Vol 1 No 2, 99107.

Alam, L., 2016, Internalisasi Nilai-Nilai Pendidikan Islam Dalam Perguruan Tinggi Umum Melalui Lembaga Dakwah Kampus, ISTAWA: Jurnal Pendidikan Islam Vol 1 No 2, 101-120.

Allport, G. W., 1950, The Individual And His Religion, MacMillan, New York.

Allport, G. W., Ross, J. M., 1967, Personal Religious Orientation And Prejudice, Journal of Personality 
and Social Psychology Vol 5, 432-443.

Amaliah, I., Aan J., Westi R., 2013, Pengaruh Nilai Islam Terhadap Kinerja Kerja, Jurnal Mimbar Vol 29 No 2, 165-174.

Amilin, 2016, Dampak Penerapan Good University Governance Terhadap Kinerja Manajerial Melalui Implementasi Anggaran Berbasis Partisipatif, Jurnal Akuntansi Vol XX No 03, 330-344.

Basri, Y. M., 2015, Pengaruh Gender, Religiusitas Dan Sikap Love Of Money Pada Persepsi Etika Penggelapan Pajak Mahasiswa Akuntansi, Jurnal Ilmiah Akuntansi dan Bisnis Vol 10 No 1, 45-54.

Berkah, D., 2014, Implementasi Prinsip Islamic Corporate Governance Dalam Pedoman Amal Usaha Kesehatan, Jurnal Ahkam, Vol 2 No 1, 89-104.

Budiarto, D. S., Yennisa., Widyaningrum., R., 2018, Does Religiosity Improve Tax Compliance?; An empirical research based from gender, Jurnal Dinamika Akuntansi, Vol. 10, No. 1, 82-90.

Chowdhury, R. M., 2018, Religiosity and Voluntary Simplicity: The Mediating Role of Spiritual WellBeing, Journal of Business Ethics, Vol 152, 149-174.

Fauzan, 2013, Pengaruh Religiusitas Terhadap Etika Berbisnis, Jurnal Manajemen dan Kewirausahaan Vol 15 No 1, 53-64.

Hafizhah, I., Yessi M. B., Rusli, 2016, Pengaruh Etika Uang (Money
Ethics) Terhadap Kecurangan Pajak (Tax Evasion) Dengan Religiusitas, Gender, dan Materialisme Sebagai Variabel Moderasi, JOM FEKON Vol 3 No 1, 1652-1665.

Hamzah, G., Siswoyo H., Zainal M. EQ, 2018, The Effects of Good University Governance and Organizational Culture Toward Lecturer Performance and Its Influence on Private Universities Performance in the City of Lampung, European Jurnal of Business and Management Vol 10 No 21, 85-94.

Hatmodjosoewito, J. S., 2010, Hubungan Antara Transparansi Pengelolaan Universitas Dengan Kinerja Karyawan Dalam Rangka Menciptakan Good University Governance, Jurnal Ilmiah Manajemen Bisnis Vol 10 No 1, 118.

McDaniel, S. W., Burnett, J. J., 1990, Consumer Religiosity and Retail Store Evaluative Criteria, Journal Of The Academy of Marketing Science Vol 18 No 2, 101-112.

Nikmatuttisaroh, A, 2014, Pengaruh Motivasi, Pengetahuan Akuntansi, dan Religiusitas Terhadap Kualitas Lulusan Program Studi Akuntansi Syariah, Jurnal Akuntansi dan Keuangan Islam Vol 2 No 1, 65-82.

Nulhaqim et al, 2015, Peranan Perguruan Tinggi Dalam Meningkatkan Kualitas Pendidikan Di Indonesia Untuk Menghadapi ASEAN COMMUNITY 2015 (Studi Kasus: Universitas Indonesia, Universitas Padjadjaran, Institut Teknologi 
Jurnal Ilmiah Ekonomi dan Bísnis

Vol. 16. No.2, September 2019: 110-121

EISSN : $2442-9813$

ISSN : $1829-9822$

Bandung), Social Work Jurnal Vol 6 No 2, 154-272.

Pemayun, A. A. G. A. W., I Gusti, A. N. B., 2018, Pengaruh Religiusitas, Status Sosial Ekonomi dan Love Of Money Pada Persepsi Etis Mahasiswa Akuntansi, E-Jurnal Akuntansi Universitas Udayana Vol 23 No 2, 1600-1628.

Peterson, R.A., Albaum, J.Merunka, D., Munuera, J.L., Smith, S.M., 2010, Effects of Nationality, Gender, and Religiosity on Business-Related Ethicality, Journal of Business Ethics Vol 96(4), 573-587.

Prasetyo, 2014, Dampak Kebijakan Akreditasi Perguruan Tinggi Terhadap Daya Saing (Competitiveness) Perguruan Tinggi Swasta di Kabupaten Kebumen, Jurnal Fokus Bisnis Vol 13, 31-42.

Putri, N. T., Elita A., Adlina S. H., 2015, Pengaruh Akreditasi Perguruan Tinggi Terhadap Kepuasan dan Loyalitas Mahasiswa (Studi Kasus: $\quad$ Fakultas Teknik Universitas Andalas), Seminar Nasional Pengembangan Pendidikan Tinggi Padang 6-7 Agustus, 245-258.

Rosyid, A., Agus, F., Miftahul H., 2014, Survei Atas Implementasi Good University Governance, Jurnal Penelitian Vol 11 No 1, 172-188.

Silahuddin, 2016, Perbedaan Tingkat Religiusitas Mahasiswa Di Perguruan Tinggi Keagamaan Islam Negeri dan Perguruan Tinggi Umum Negeri Di Provinsi Aceh Tahun 2016, Lembaga
Penelitian dan Pengabdian Kepada Masyarakat Universitas Islam Negeri Ar-Raniry Banda Aceh.

Singhapakdi, A., Scott J. V., Dong J. L., Amiee M. N., Grace B. Y., 2013, The Influence of Love of Money and Religiosity on Ethical Decision-Making in Marketing, Journal of Business Ethics, Vol 114, 183-191.

Stavrova, O., Siegers, P., 2014, Religious prosociality and morality across cultures: How social enforcement of religion shapes the effects of personal religiosity on prosocial and moral attitudes and behaviors, Personality and Social Psychology Bulletin 40(3), 315-333.

Sugiyono, 2010, Metodologi Penelitian Bisnis, Alfabeta, Bandung.

Suherman, U. D., 2018, Pengaruh Penerapan Nilai-Nilai Islami dan Komitmen Organisasional Terhadap Kinerja Karyawan Pemasaran Bank Umum Syariah di Jawa Barat, Economica: Jurnal Ekonomi Islam Vol 9 No 1, 51-81.

Syukri, Fathudin A. W., Sudiyatno, 2009, Peningkatan Perilaku Religius Melalui Integrasi Pembelajaran PAI dan Pembinaan di Unit Kegiatan Keagamaan Mahasiswa, Jurnal Humanika Vol. 9 No. 1, 5366.

Tang, T. L. P., Chen, Y. J., 2008, Intelligence vs wisdom: The love of money, machiavellianism, and unethical behavior across college major and gender, Journal of Business Ethics 82(1), 1-26. 
Wahyudin, A., Ahmad N., Kiswanto, 2017, Hubungan Good University Governance Terhadap Kinerja Manajemen Keuangan Perguruan Tinggi, Jurnal Keuangan dan Perbankan Vol 21 No 1, 60-69.

Walker, A. G., James W. S., Jason D., 2012, The Effect of Religiosity on Ethical Judgments, Journal of Business Ethics 106, 437-452.

Weaver, G. R., Agle, B. R., 2002, Religiosity and ethical behavior in organizations: A symbolic interactionist perspective, Academy of Management Review 27 (1), 77-97.

Westbrook, K. W., Steven Arendall, C., Padelford, W. M., 2011, Gender, Competitiveness, and Unethical Negotiation Strategies, Gender in Management: An International Journal 26(4), 289-310.

Wibisono, S., Muhammad T., 2017, Orientasi Keberagamaan Ekstrinsik Dan Fundamentalisme Agama Pada Mahasiswa Muslim: Analisis Dengan Model Rasch, Jurnal Psikologi Sosial Vol 15 No 01, 1-11.

Widjajanti, K., Eviatiwi K. S., 2015, Good University Governance Untuk Meningkatkan Excellent Service Dan Kepercayaan Mahasiswa, Jurnal Dinamika Sosbud Vol 17 No 2, 69-8 